\title{
A preliminary study of schema therapy for adults with high-functioning autism spectrum disorder: A single-arm, uncontrolled trial
}

\section{Fumiyo Oshima ( $\nabla$ f_oshima@chiba-u.jp )}

Chiba University

\section{Tomokazu Murata}

Chiba University

\section{Toshiyuki Ohtani}

Chiba University

\section{Mikuko Seto}

Chiba University

\section{Eiji Shimizu}

Chiba University

\section{Research note}

Keywords: autism spectrum disorder, schema therapy, social functioning, quality of life

Posted Date: December 31st, 2020

DOl: https://doi.org/10.21203/rs.3.rs-136824/v1

License: (a) (i) This work is licensed under a Creative Commons Attribution 4.0 International License.

Read Full License 


\section{Abstract}

Objective: Schema therapy (ST) has recently been shown to be effective for the treatment of various mental disorders, including personality disorders. This pilot clinical trial aimed to explore the feasibility, acceptability, and effectiveness of ST for adults with high-functioning autism spectrum disorder (HF-ASD)

Results: From pre- to post-treatment, we found significant improvements in social functions (GAF and WHO-QOL), early maladaptive schema (YSQ), and depression and anxiety (BDI-II and STAI).

Trial registration: UMIN000014535; registered on July 11, 2014.

\section{Introduction}

Autism spectrum disorder (ASD) is a neurodevelopmental disorder with persistent deficits in social communication and social interaction based on the Diagnostic and Statistical Manual of Mental Disorders, Fifth Edition (DSM-5) [1]. ASD adults tend to have difficulties with social functioning, contributing to poor quality of life (QOL) [2]. ASD children diagnosed before the age of 10 years tend to have higher psychosocial QOL than those who are not [3].

Unfortunately, most high-functioning ASD (HF-ASD) individuals remain undiagnosed at early ages because of high-functioning [4], signifying that they do not receive appropriate support, as symptoms remain unnoticed for the same reason $[5,6]$. Unawareness of their ASD traits could result in innate inferior traits and self-stigmatization, which may increase depression and anxiety [7].

Psychological interventions for ASD are classified into treatment for its core symptoms and related symptoms [8-10], with early interventions fundamental to the success of both [11]. Regarding treatment for the latter, cognitive-behavioral therapy (CBT) targeting ASD-related anxiety is ineffective [12]. Moreover, studies have shown that ASD after puberty is characterized by strong self-stigmatization due to chronic social isolation [13]. Since CBT is a symptom-specific treatment, it is not widely available for chronic maladjustment based on ASD. Therefore, improving CBT for ASD individuals is clinically important.

Schema therapy (ST) [14], an innovative and integrative psychotherapy model, is used to treat those who face difficulties with personality disorder diagnoses [15-20]. ST is composed of early maladaptive schema (EMS), schema mode, limited reparenting, and core emotional needs [21, 22]. EMS is an excessively generalized cognitive and emotional system composed of innate features and early childhood experiences. When an individuals' core needs are unfulfilled in early childhood, they can form multiple EMSs, which exert a schema mode that temporarily comes to the fore and dominates their presentation, resulting in difficulties in interpersonal relationships [23]. We previously confirmed that individuals with HFASD EMSs had almost all EMSs. As EMSs are assumed to be the core of the psychopathology of HF-ASD and personality disorders, learning how to change EMS into more adaptive ones, and utilizing their adaptive coping responses, is the ultimate goal of ST [24]. The therapeutic purpose of ST is to cultivate a more constructive "healthy adult mode" (instead of schema mode) toward environmental stimuli by gratifying patients' core needs using "limited reparenting." ST, a structured type of psychotherapy, is 
effective $[15,25,26]$ and suitable for many psychiatric disorders; HF-ASD adults are now considered suitable for ST, as they generally benefit from structured settings [27]. In this study, an author, Oshima, identified EMSs specific to HF-ASD individuals [28]. However, studies on the clinical efficacy of ST for HFASD are inadequate. Thus, this pilot study aimed to utilize ST for adults with HF-ASD and examine its feasibility and efficacy in improving patients' social functioning.

\section{Materials And Methods}

This was a preliminary study with a single-arm and open trial design for examining the feasibility of ST for the treatment of HF-ASD in a Japanese clinical setting.

\section{Participants}

Participants $(n=13)$ were recruited through psychiatrist referral at the Safety and Health Organization, Chiba University, and Chiba University Hospital, Chiba, Japan. The inclusion criteria were: age between 18-40 years, intelligence quotient (IQ) of at least 80 (Wechsler Adult Intelligence Scale III [WAIS-III]) [29], and an ASD diagnosis based on the Autism Diagnostic Interview-Revised [30] and/or the Autism Diagnostic Observation Schedule - Second Edition [31]. The Mini-International Neuropsychiatric Interview [32] was used to evaluate comorbid psychiatric conditions. The exclusion criteria were: a history of substance abuse, active suicidality, and severe mental and physical conditions. Participants were adults of average intelligence with ASD, and could respond on their own initiative after understanding the reason for obtaining research consent.

\section{Procedures}

Recruitment, treatment, and data collection were conducted between September 2014 and March 2018; the trial flow chart is shown in Fig. 1. Each weekly session lasted 50 minutes (Additional File 1). A follow-up interview was conducted 12 weeks after intervention completion (37th week).

\section{Treatment outcome}

The primary outcome measures were the Global Assessment Functioning (GAF) Scale [33], an interview rating of social functioning, World Health Organization quality of life assessment brief (WHO QOL-BREF) [34], and a self-rating scale measuring subjective feeling of social adaptiveness and QOL. The secondary outcomes were the scores of the Young Schema Questionnaire-Short Form 3 (YSQ-SF) [35] and the Schema Mode Inventory (SMI) [36], which measure the EMSs and the schema modes of patients, respectively. Other outcome variables measuring comorbid symptoms, such as depression, anxiety, and obsessive-compulsive symptoms, were assessed by the Beck Depression Inventory II (BDI-II) [37], the StateTrait Anxiety Inventory (STAI) [38], Liebowitz Social Anxiety Scale (LSAS) [39], and Obsessive-Compulsive Inventory [40], respectively. Permission was not needed to use these questionnaires.

\section{Analysis}


The data were analyzed using repeated-measures analyses of variance (ANOVAs) with time as the independent variable. In addition, a paired t-test adjusted by a Bonferroni correction was used for pairwise comparisons. For the primary outcomes and other comorbid symptom measurements, the adjusted a value was $a=.05 / 3 / 9=.002$. For the secondary outcomes, the adjusted a value was $a=.05 / 3 / 23=.0007$ for YSQ-SF and $a=.05 / 3 / 16=.001$ for SMI, respectively. Effect sizes were calculated for changes in scale scores between time points (Cohen's $d$ ). All analyses were conducted using SPSS for Windows version 23 (IBM, Armonk, NY, USA).

\section{Results}

\section{Patients' demographics and baseline data}

Among thirteen patients, three dropped out, leaving ten patients (Fig. 1). The participants were aged 20 to 39 years, and met the DSM- 5 criteria for ASD (Table 1 and Additional File 2). 
Table 1

Baseline demographic and clinical characteristics.

\begin{tabular}{|c|c|}
\hline Variable & Mean (SD) / Frequency (\%) \\
\hline Age & $26.8(6.39)$ \\
\hline \multicolumn{2}{|l|}{ Sex } \\
\hline Female & $5(50 \%)$ \\
\hline Male & $5(50 \%)$ \\
\hline \multicolumn{2}{|l|}{ Education } \\
\hline Master & $2(20 \%)$ \\
\hline Bachelor & $7(70 \%)$ \\
\hline High school & $1(10 \%)$ \\
\hline \multicolumn{2}{|l|}{ Employment } \\
\hline Student & $7(70 \%)$ \\
\hline Part timer & $1(10 \%)$ \\
\hline Unemployed & $2(20 \%)$ \\
\hline \multicolumn{2}{|l|}{ Diagnosis } \\
\hline$A S D+O C D$ & $4(40 \%)$ \\
\hline$A S D+A D H D$ & $1(10 \%)$ \\
\hline$A S D+D E P$ & $5(50 \%)$ \\
\hline \multicolumn{2}{|l|}{ ADI-R } \\
\hline Quality of reciprocal social interaction & $16(4.22)$ \\
\hline Communication & $13.3(4.37)$ \\
\hline Repetitive, restricted, and stereotyped patterns of behavior & $3.2(1.75)$ \\
\hline Abnormalities of behavior evident at or before 36 months & $1.8(1.14)$ \\
\hline \multicolumn{2}{|l|}{ ADOS-2 } \\
\hline Communication & $3.8(1.48)$ \\
\hline Reciprocal Social Interaction & $7(2.54)$ \\
\hline
\end{tabular}

OCD, obsessive-compulsive disorder; DEP, depression; $A D H D$, attention deficit hyperactivity disorder; ADI-R, Autism Diagnostic Interview-Revised; ADOS-2, Autism Diagnostic Observation Schedule-2; WAIS3, The Wechsler Adult Intelligence Scale-3; VIQ, Verbal IQ; PIQ, Performance IQ; FIQ, Full scale IQ; VC, Verbal Comprehension; PO, Perceptual Organization; WM, Working memory; PS, Perceptual Organization 


\begin{tabular}{|ll|}
\hline Variable & Mean (SD) / Frequency (\%) \\
\hline Imagination / Creativity & $1.4(0.52)$ \\
\hline Restricted and repetitive behaviors & $1.2(0.63)$ \\
\hline WAIS-3 & $120.8(10.6)$ \\
\hline VIQ & $117.7(11.04)$ \\
\hline PIQ & $120(9.51)$ \\
\hline FIQ & 119.7 (12.31) \\
\hline VC & 120 (12.75) \\
\hline PO & 112.6 (11.16) \\
\hline WM & 109.7 (19.29) \\
\hline PS & \\
\hline $\begin{array}{l}\text { OCD, obsessive-compulsive disorder; DEP, depression; ADHD, attention deficit hyperactivity disorder; } \\
\text { ADI-R, Autism Diagnostic Interview-Revised; ADOS-2, Autism Diagnostic Observation Schedule-2; WAIS- } \\
\text { 3, The Wechsler Adult Intelligence Scale-3; VIQ, Verbal IQ; PIQ, Performance IQ; FIQ, Full scale IQ; VC, } \\
\text { Verbal Comprehension; PO, Perceptual Organization; WM, Working memory; PS, Perceptual } \\
\text { Organization }\end{array}$ \\
\hline
\end{tabular}

\section{Treatment outcomes}

The repeated-measures ANOVA revealed a significant main effect of time on the primary outcome, GAF. A post hoc analysis revealed that there were significant differences between pre-and post-treatment $(p<$ $0.001, d=3.30)$ and between pre-treatment and follow-up $(p<0.001, d=3.35)$ (Table 2). Additionally, the main effect of time for WHO QOL-BREF was significant; however, post hoc analyses result did not remain significant between each time point after the correction. 
Table 2

Changes in each evaluated item before ST, after ST, and at follow-up

\begin{tabular}{|c|c|c|c|c|c|c|c|}
\hline & Pre-ST & Post-ST & Follow- & & Cohe & & \\
\hline Variable & Mean (SD) & Mean (SD) & $\begin{array}{l}\text { Mean } \\
\text { (SD) }\end{array}$ & $F$ & $\begin{array}{l}\text { Pre- } \\
\text { ST } \\
\text { vs. } \\
\text { post- } \\
\text { ST }\end{array}$ & $\begin{array}{l}\text { Post- } \\
\text { ST vs. } \\
\text { follow- } \\
\text { up }\end{array}$ & $\begin{array}{l}\text { Pre-ST } \\
\text { vs. } \\
\text { follow- } \\
\text { up }\end{array}$ \\
\hline GAF & $\begin{array}{l}45.90 \\
(10.82)\end{array}$ & $\begin{array}{l}76.00 \\
(7.06)^{a}\end{array}$ & $\begin{array}{l}76.20 \\
(6.83)^{\mathrm{C}}\end{array}$ & $\begin{array}{l}F(1.3, \\
11.67) \\
= \\
151.65^{\star \star}\end{array}$ & 3.30 & 0.03 & 3.35 \\
\hline QOL & $\begin{array}{l}65.20 \\
(16.03)\end{array}$ & $\begin{array}{l}75.70 \\
(14.28)\end{array}$ & $\begin{array}{l}78.50 \\
(12.77)\end{array}$ & $\begin{array}{l}F(1.21, \\
10.87)^{* *} \\
=9.93^{* *}\end{array}$ & 0.69 & 0.21 & 0.92 \\
\hline BDI- $\triangle$ & $\begin{array}{l}27.70 \\
(17.54)\end{array}$ & $\begin{array}{l}16.70 \\
(13.94)\end{array}$ & $\begin{array}{l}13.00 \\
(11.76)\end{array}$ & $\begin{array}{l}F(1.16, \\
10.4)= \\
9.64^{\star \star}\end{array}$ & 0.70 & 0.29 & 0.99 \\
\hline STAI (state) & $45.20(9.47)$ & $49.70(8.21)$ & $\begin{array}{l}41.50 \\
(6.92)^{b}\end{array}$ & $\begin{array}{l}F(2, \\
18)= \\
3.93^{*}\end{array}$ & 0.51 & 1.08 & 0.45 \\
\hline STAI (trait) & $\begin{array}{l}55.80 \\
(14.16)\end{array}$ & $\begin{array}{l}53.00 \\
(10.53)\end{array}$ & $\begin{array}{l}47.50 \\
(8.82)\end{array}$ & $\begin{array}{l}F(2, \\
18)= \\
3.56^{*}\end{array}$ & 0.23 & 0.57 & 0.70 \\
\hline $\mathrm{OCl}$ & $\begin{array}{l}67.70 \\
(30.94)\end{array}$ & $\begin{array}{l}59.40 \\
(27.39)\end{array}$ & $\begin{array}{l}49.70 \\
(23.15)\end{array}$ & $\begin{array}{l}F(1.17, \\
10.49) \\
=3.98\end{array}$ & 0.29 & 0.38 & 0.66 \\
\hline LSAS_Total & $\begin{array}{l}62.70 \\
(22.60)\end{array}$ & $\begin{array}{l}62.80 \\
(27.53)\end{array}$ & $\begin{array}{l}50.70 \\
(18.64)\end{array}$ & $\begin{array}{l}F(1.2, \\
10.81) \\
=2.71\end{array}$ & 0.00 & 0.52 & 0.58 \\
\hline LSAS_fear/anxiety & $\begin{array}{l}35.90 \\
(13.54)\end{array}$ & $\begin{array}{l}35.40 \\
(15.18)\end{array}$ & $\begin{array}{l}27.20 \\
(9.32)\end{array}$ & $\begin{array}{l}F(2 \\
18)= \\
5.22^{*}\end{array}$ & 0.04 & 0.65 & 0.75 \\
\hline
\end{tabular}

Note: ${ }^{* *} p<0.01,{ }^{*} p<0.05$ calculated using analysis of variance

a: Significant difference between pre- and post-intervention values ( $p<.05$, Bonferroni corrected), b: Significant difference between post-intervention and follow-up values, c: Significant difference between pre-intervention and follow-up values $(p<.05$, Bonferroni corrected).

BDI-II, Beck Depression Inventory-II; STAI (State), State items from the State-Trait Anxiety Inventory; STAI (Trait), Trait items from the State-Trait Anxiety Inventory; OCl, Obsessive Compulsive Inventory; LSAS (Total score), Total items from the Liebowitz Social Anxiety Scale; LSAS (Fear/Anxiety), Fear and anxiety items from the Liebowitz Social Anxiety Scale; LSAS (Avoidance), Avoidance items from the Liebowitz Social Anxiety Scale 


\begin{tabular}{|c|c|c|c|c|c|c|c|}
\hline \multirow{2}{*}{ LSAS_escape } & \multirow{2}{*}{$\begin{array}{l}\text { Pre-ST } \\
26.80(13.23)\end{array}$} & \multirow{2}{*}{$\begin{array}{l}\text { Post-ST } \\
27.40(13.70)\end{array}$} & \multirow{2}{*}{$\begin{array}{l}\text { Follow- } \\
\text { up } \\
23.50 \\
(11.21)\end{array}$} & \multicolumn{4}{|c|}{ Cohen's $d$} \\
\hline & & & & $\begin{array}{l}F(1.27 \\
11.46) \\
=0.59\end{array}$ & 0.05 & 0.31 & 0.27 \\
\hline \multicolumn{8}{|c|}{ Note: ${ }^{*} p<0.01,{ }^{*} p<0.05$ calculated using analysis of variance } \\
\hline \multicolumn{8}{|c|}{$\begin{array}{l}\text { a: Significant difference between pre- and post-intervention values ( } p<.05 \text {, Bonferroni corrected), b: } \\
\text { Significant difference between post-intervention and follow-up values, } c \text { : Significant difference } \\
\text { between pre-intervention and follow-up values ( } p<.05 \text {, Bonferroni corrected). }\end{array}$} \\
\hline \multicolumn{8}{|c|}{$\begin{array}{l}\text { BDI-II, Beck Depression Inventory-II; STAI (State), State items from the State-Trait Anxiety Inventory; } \\
\text { STAI (Trait), Trait items from the State-Trait Anxiety Inventory; OCI, Obsessive Compulsive Inventory; } \\
\text { LSAS (Total score), Total items from the Liebowitz Social Anxiety Scale; LSAS (Fear/Anxiety), Fear and } \\
\text { anxiety items from the Liebowitz Social Anxiety Scale; LSAS (Avoidance), Avoidance items from the } \\
\text { Liebowitz Social Anxiety Scale }\end{array}$} \\
\hline
\end{tabular}

Regarding the secondary outcomes, the repeated-measures ANOVA revealed a significant effect of time on the YSQ-SF (Total score), Disconnection and rejection, Impaired autonomy and performance, Impaired limits (Over-vigilance and inhibition), Social Isolation/Alienation schema, Failure schema,

Dependence/Incompetence schema, Emotional Inhibition schema, Approval-Seeking/Recognition-Seeking schema, Negativity/Pessimism schema, and Punitiveness schema scores, but not on other subscales (Additional File 3). The Bonferroni post hoc test showed a significant difference between pre-treatment and the follow-up ( $p=0.00048, d=1.01)$ for the YSQ-SF (Total score). Similarly, for Disconnection and rejection, a significant difference was found between post-treatment and follow-up $(p=0.00026, d=0.34)$. There was also a significant difference for Impaired limits (Over-vigilance and inhibition) between pretreatment and follow-up $(p=0.00002, d=0.63)$. In addition, for the Emotional Inhibition schema and the Negativity/Pessimism schema, although the ANOVA showed a significant main effect of time, the Bonferroni post hoc test did not show any significance.

Regarding the SMI, the repeated-measures ANOVA revealed a significant main effect of time for the Adaptive mode, Maladaptive mode, Vulnerable child mode, Angry child mode, Enraged child mode, Impulsive child mode, Undisciplined child mode, Happy child mode, Compliant surrenderer mode, Detached protector modes, Self-aggrandizer mode, Punitive parent mode, Demanding parent mode, and Healthy adult mode scores (Additional File 4).

Conversely, there was no significant difference in the Detached self-soothing or Bullying and attack modes. Bonferroni post hoc tests showed a significant difference between pre-treatment and follow-up for the Maladaptive mode $(p=0.00051, d=1.57)$, Enraged child mode, $(p=0.00012, d=1.86)$, Undisciplined child mode $(p=0.00066, d=0.97)$, and Demanding parent mode $(p=0.00010, d=1.10)$.

Regarding other outcomes, significant effects of time were observed for BDI-II, STAI-state and -trait, and LSAS fair/anxiety; however, post hoc comparison with Bonferroni correction did not remain significant 
between each time point. No aversive reports or effects were observed; thus, ST can be implemented and adapted for short-term use in outpatient settings for adults with HF-ASD.

\section{Discussion}

The results suggest that ST for HF-ASD adult patients significantly affected their social functioning and subjective well-being. Additionally, we proved that ST could be implemented and adapted for short-term use in outpatient settings for HF-ASD adults. We observed large effect size for the GAF score from pre- to post-intervention and from pre-intervention to follow-up $(d s=3.30$ and 3.35). Although the improvement in subjective well-being was not statistically significant after Bonferroni adjustments, the effect sizes were large from pre- to post-intervention and from pre-intervention to follow-up ( $d s=0.69$ and 0.92 ). Seven patients indicated social participation, such as returning to school or removing themselves from selfimposed isolation and receiving employment support. It may take time for HF-ASD individuals to realize their social functioning improvements, and therefore, sharing their achievements in real-life during sessions would be an important component. Moreover, our results showed that ST was effective for the total score of YSQ, Disconnection and rejection subscale, and Impaired limits subscale. ST was developed to influence individuals' EMS. Our results indicated that ST for HF-ASD may improve individuals' disconnected feelings with others or the social environment, and enhance their self-control abilities. Subscales of EMSs in which individuals with ASD scored higher than individuals without were social isolation, failure, and dependence-incompetence [28]. The results of this study showed that these three EMSs were significantly reduced after the intervention. Moreover, they are considered to influence communication style and social relationships [28], and improvement in EMSs along with that of social functioning may be important ST outcomes for HF-ASD. Additionally, we found that ST for HF-ASD showed significant improvement in several subscales in SMI. Interestingly, these changes were statistically significant only from pre-intervention to follow-up, not from pre- to post-intervention. Since the schema mode is more stable than EMS, changes in the former may have delayed effects. When considering the underlying mechanisms of delayed improvement in SMI, decreased scores in the Enraged child, Undisciplined child, and Demanding parent mode may have reduced individual irritability and aggressive behavior, leading to less social interaction-related problems. Moreover, the maladaptive coping mode can enhance avoidance behaviors and/or over-adaptations, and the reduced maladaptive coping mode via ST may enable individuals to participate socially. The schema mode, being more rigid, can highlight CBT failures, as it does not usually treat schemas. Thus, ST is a unique therapeutic approach for changing patient schema modes.

Finally, we did not observe any significant improvement in comorbid symptoms after ST. Since baseline scores for those measurements were not high compared with patients with major depressive disorder, anxiety disorder, and obsessive-compulsive disorder, those with comorbid symptoms may not have improved. However, among ASD individuals, the effects of CBT on depression and anxiety are likely to be diminished by the ASD status [12], and if we utilize ST for HF-ASD adults with severe mood disorders, ST may be useful in enhancing their social participation. 


\section{Limitations}

The single-arm design without control groups restricted the comparison of this study with other psychological interventions, in terms of the clinical efficacy of ST on social adaptations. Additionally, the sample size was small, and controls were not used during secondary diagnoses. Therefore, the therapeutic efficacy of this study may be limited. Finally, it may be difficult to exclusively determine the efficacy of ST on social adaptiveness from this study. Since ST involves psychoeducation about ASD traits, the component of psychoeducation may influence social adaptiveness along with ST per se. ST targets maladaptive schemas at the deepest cognition level, and is considered better equipped to enable dysfunctional schematic processing changes at the schema level. For example, ST showed clinical efficacy in treatment-resistant patients, such as those with personality disorders [41]. Therefore, we suggest that ST may be effective in enhancing ASD adults' awareness and acceptance of their ASD traits, which may also influence their social adaptiveness. Future studies with mediation analysis and randomized controlled trials are needed to understand the underlying mechanisms of ST for HF-ASD.

\section{Abbreviations}

ASD

autism spectrum disorder

BDI-II

Beck Depression Inventory II

CBT

cognitive-behavioral therapy

DSM-5

diagnostic and statistical manual of mental disorders

EMS

early maladaptive schema

GAF

global assessment functioning

HAM

healthy adult mode

HF-ASD

high-functioning autism spectrum disorder

IQ

intelligence quotient

QOL

quality of life

SMI

Schema Mode Inventory

ST

schema therapy 
WAIS-III

Wechsler Adult Intelligence Scale III

WHO QOL-BREF

World Health Organization Quality Of Life Assessment Brief

YSQ-SF

Young Schema Questionnaire Short Form 3

\section{Declarations}

Ethics approval and consent to participate: This trial was approved by the Chiba University Clinical Research Ethical Review Committee (No.1867). Written informed consent was obtained from the participants, by providing a consent form approved by the Chiba University Clinical Research Ethical Committee, following a verbal explanation of the trial along with the consent form. All personal information (including anonymized data) were treated as confidential. Participants could access these data after the follow-up upon request. This clinical trial was registered on the University Hospital Medical Information Network Center (No. UMIN000014535). The Chiba University Clinical Research Ethical Committee reviewed the study protocol. All sessions and psychological examinations were provided free of charge to the participants.

Consent for publication: Not applicable.

Availability of data and materials: The datasets used and/or analyzed during the current study are available from the corresponding author on reasonable request.

Competing interests: The authors declare that they have no competing interests.

Funding: The study was supported by the Grant-in-Aid for Young Scientists (B) (15K17290) of the Japan Society for the Promotion of Science in Japan. The funders had no role in the design of the study and collection, analysis, and interpretation of data or in writing the manuscript.

Author contributions: Study concept and design: FO. Statistical analysis for study design: TM. Drafting of the manuscript: FO \& KS. Critical revision of the manuscript: HO. Study therapists: FO. Study supervision: ES. All the authors have approved the submitted version and any substantially modified version that involves the author's contribution to the study. All authors have agreed to be personally accountable for their own contributions and to ensure that questions related to the accuracy or integrity of any part of the work, even ones in which the author was not personally involved, are appropriately investigated, resolved, and the resolution documented in the literature.

Acknowledgments: Our deep appreciation is extended to Ida Shaw at the Schema Therapy Institute Midwest-Indianapolis and to Aki Tsuchiyagaito at the Laureate Instituto for Brain Research, Tulsa, for their immense contribution to this investigation. 


\section{References}

1. American Psychiatric Association, DSM-5 Task Force. (2013). Diagnostic and statistical manual of mental disorders: DSM- ${ }^{\mathrm{TM}}$ (5th ed.). American Psychiatric Publishing, Inc. doi:10.1176/appi.books.9780890425596.

2. Lever AG, Geurts HM. Psychiatric co-occurring symptoms and disorders in young, middle-aged, and older adults with autism spectrum disorder. J Autism Dev Disord. 2016; doi:10.1007/s10803-0162722-8.

3. Kamio Y, Inada N, Koyama T. A nationwide survey on quality of life and associated factors of adults with high-functioning autism spectrum disorders. Autism. 2013; doi:10.1177/1362361312436848.

4. Bargiela S, Steward R, Mandy W. The experiences of late-diagnosed women with autism spectrum conditions: an investigation of the female autism phenotype. J Autism Dev Disord. 2016; doi:10.1007/s10803-016-2872-8.

5. Calzada LR, Pistrang N, Mandy, WPL. High-functioning autism and Asperger's disorder: utility and meaning for families. J. Autism Dev Disord. 2012; doi:10.1007/s10803-011-1238-5.

6. Murphy CM, Wilson CE, Robertson DM, Ecker C, Daly EM, Hammond N, et al. Autism spectrum disorder in adults: diagnosis, management, and health services development. Neuropsychiatr Dis Treat. 2016; doi:10.2147/NDT.S65455.

7. Hayes J, Ford T, Rafeeque H, Russell G. Clinical practice guidelines for diagnosis of autism spectrum disorder in adults and children in the UK: a narrative review. BMC Psychiatry. 2018; doi:10.1186/s12888-018-1800-1.

8. Russell AJ, Jassi A, Fullana MA, Mack H, Johnston K, Heyman I, et al. Cognitive behavior therapy for comorbid obsessive-compulsive disorder in high-functioning autism spectrum disorders: a randomized controlled trial. Depress Anxiety. 2013; doi:10.1002/da.22053.

9. Spain D, Sin J, Chalder T, Murphy D, Happé F. Cognitive behaviour therapy for adults with autism spectrum disorders and psychiatric co-morbidity: a review. Res. Autism Spectr Disord. 2015; doi:10.1016/J.RASD.2014.10.019.

10. Sizoo BB, Kuiper E. Cognitive behavioural therapy and mindfulness based stress reduction may be equally effective in reducing anxiety and depression in adults with autism spectrum disorders. Res Dev Disabil. 2017; doi:10.1016/J.RIDD.2017.03.004.

11. Estes A, Munson J, Rogers SJ, Greenson J, Winter J, Dawson G. Long-term outcomes of early intervention in 6-year-old children with autism spectrum disorder. J Am Acad Child Adolesc Psychiatry. 2015; doi:10.1016/j.jaac.2015.04.005.

12. Tsuchiyagaito A, Hirano Y, Asano K, Oshima F, Nagaoka S, Takebayashi Y, et al. Cognitive-behavioral therapy for obsessive-compulsive disorder with and without autism spectrum disorder: Gray matter differences associated with poor outcome. Front Psychiatry. 2017; doi:10.3389/fpsyt.2017.00143.

13. Someki F, Torii M, Brooks PJ, Koeda T, Gillespie-Lynch K. Stigma associated with autism among college students in Japan and the United States: An online training study. Res Dev Disabil. 2018; 
doi:10.1016/j.ridd.2018.02.016.

14. Young J. Cognitive therapy for personality disorders: a schema- focused approach. Sarasota, FL: Professional Resource Exchange, Inc.; 1990.

15. Carter JD, Mclntosh VV, Jordan J, Porter RJ, Frampton CM, Joyce PR. Psychotherapy for depression: a randomized clinical trial comparing schema therapy and cognitive behavior therapy. J Affect Disord. 2013; doi:10.1016/j.jad.2013.06.034.

16. Giesen-Bloo J, van Dyck R, Spinhoven P, van Tilburg W, Dirksen C, van Asselt T, et al. Outpatient psychotherapy for borderline personality disorder: randomized trial of schema-focused therapy vs transference-focused psychotherapy. Arch Gen Psychiatry. 2006; doi:10.1001/archpsyc.63.6.649.

17. van Asselt AD, Dirksen CD, Arntz A, Giesen-Bloo JH, van Dyck R, Spinhoven P, et al. Out-patient psychotherapy for borderline personality disorder: cost-effectiveness of schema-focused therapy v. transference-focused psychotherapy. Br J Psychiatry. 2008; doi:10.1192/bjp.bp.106.033597.

18. Farrell JM, Shaw IA, Webber MA. A schema-focused approach to group psychotherapy for outpatients with borderline personality disorder: a randomized controlled trial. J Behav Ther Exp Psychiatry. 2009; doi:10.1016/j.jbtep.2009.01.002.

19. Nadort M, Arntz A, Smit JH, Giesen-Bloo J, Eikelenboom M, Spinhoven P, et al. Implementation of outpatient schema therapy for borderline personality disorder: study design. BMC Psychiatry. 2009; doi:10.1186/1471-244X-9-64.

20. Masley SA, Gillanders DT, Simpson SG, Taylor MA. A systematic review of the evidence base for schema therapy. Cogn Behav Ther. 2012; doi: 10.1080/16506073.2011.614274.

21. Schmidt NB, Joiner TE. Global maladaptive schemas, negative life events, and psychological distress. J Psychopathol Behav Assess. 2004; doi:10.1023/B:JOBA.0000007457.95008.d2.

22. Halvorsen $M$, Wang $C E$, Eisemann $M$, Waterloo K. Dysfunctional attitudes and early maladaptive schemas as predictors of depression: a 9-year follow-up study. Cognit Ther Res. 2010; doi:10.1007/s10608-009-9259-5.

23. Young, JE, Klosko J, Weishaar M.E. Schema therapy: a practitioners guide. New York, NY: Guilford; 2003.

24. Renner F, Arntz A, Leeuw I, Huibers M. Treatment for chronic depression using schema therapy. Clin Psychol (New York). 2013; doi:10.1111/cpsp.12032.

25. Cockram DM, Drummond PD, Lee CW. Role and treatment of early maladaptive schemas in Vietnam veterans with PTSD. Clin Psychol Psychother. 2010; doi:10.1002/cpp.690.

26. Simpson SG, Morrow E, van Vreeswijk M, Reid C. Group schema therapy for eating disorders: a pilot study. Front Psychol. 2010; doi:10.3389/fpsyg.2010.00182.

27. Vuijk R, Arntz A. Schema therapy as treatment for adults with autism spectrum disorder and comorbid personality disorder: protocol of a multiple-baseline case series study testing cognitive-behavioral and experiential interventions. Contemp Clin Trials Commun. 2017; doi:10.1016/j.conctc.2017.01.001.

28. Oshima F, Iwasa K, Nishinaka H, Shimizu E. Early maladaptive schemas and high-functioning Autism Spectrum Disorders in adults. Evidence Psychother. 2015;15(2):191-205】 
29. Ryan JJ, Sattler JM, Lopez SJ. Age effects on Wechsler Adult Intelligence Scale-III subtests. Arch Clin Neuropsychol. 2000; doi:10.1016/S0887-6177(99)00019-0.

30. Lord C, Rutter M, Le Couteur A. Autism Diagnostic Interview-Revised: a revised version of a diagnostic interview for caregivers of individuals with possible pervasive developmental disorders. J Autism Dev Disord. 1994; doi:10.1007/BF02172145.

31. Lord C, Rutter M, DiLavore P, Risi S, Gotham K, Bishop S. Autism diagnostic observation schedule (ADOS-2). 2nd ed. Los Angeles: Western Psychological Corporation; 2012.

32. Sheehan DV, Lecrubier Y, Harnett Sheehan K, Janavs J, Weiller E, Keskiner A, et al. The validity of the Mini International Neuropsychiatric Interview (MINI) according to the SCID-P and its reliability. Eur Psychiatry. 1997; doi:10.1016/S0924-9338(97)83297-X.

33. Aas IM. Global Assessment of Functioning (GAF): properties and frontier of current knowledge. Ann Gen Psychiatry. 2010; doi:10.1186/1744-859X-9-20.

34. The WHOQOL Group. The World Health Organization quality of life assessment (WHOQOL): Development and general psychometric properties. Soc Sci Med. 1998; doi:10.1016/S02779536(98)00009-4.

35. Oshima F, Iwasa K, Nishinaka H, Suzuki T, Umehara S, Fukui I, et al. Factor structure and reliability of the Japanese version of the Young Schema Questionnaire Short Form. Rev Int J Psycol Ter Psycol. 2018;18:99-109.

36. Lobbestael J, van Vreeswijk M, Spinhoven P, Schouten E, Arntz A. Reliability and validity of the short Schema Mode Inventory (SMI). Behav Cogn Psychother. 2010; doi:10.1017/S1352465810000226.

37. Beck AT, Steer RA, Brown GK. BDI-II, Beck depression inventory: Manual. San Antonio, TX: Psychological Corporation; 1996.

38. Spielberger CD, Gorsuch RL, Lushene RE. STAI manual for the State-trait anxiety inventory ("selfevaluation questionnaire"). California: Consulting Psychologists Press; 1970.

39. Liebowitz MR. Social phobia. Mod Probl Pharmacopsychiatry. 1987;22:141-73.

40. Foa EB, Kozak MJ, Salkovskis PM, Coles ME, Amir N. The validation of a new obsessive-compulsive disorder scale: The obsessive-compulsive inventory. Psychol Assess. 1998; doi:10.1037/10403590.10.3.206.

41. Taylor CD J, Bee P, Haddock G. Does schema therapy change schemas and symptoms? A systematic review across mental health disorders. Psychol Psychother. 2017; doi:10.1111/papt.12112

\section{Figures}



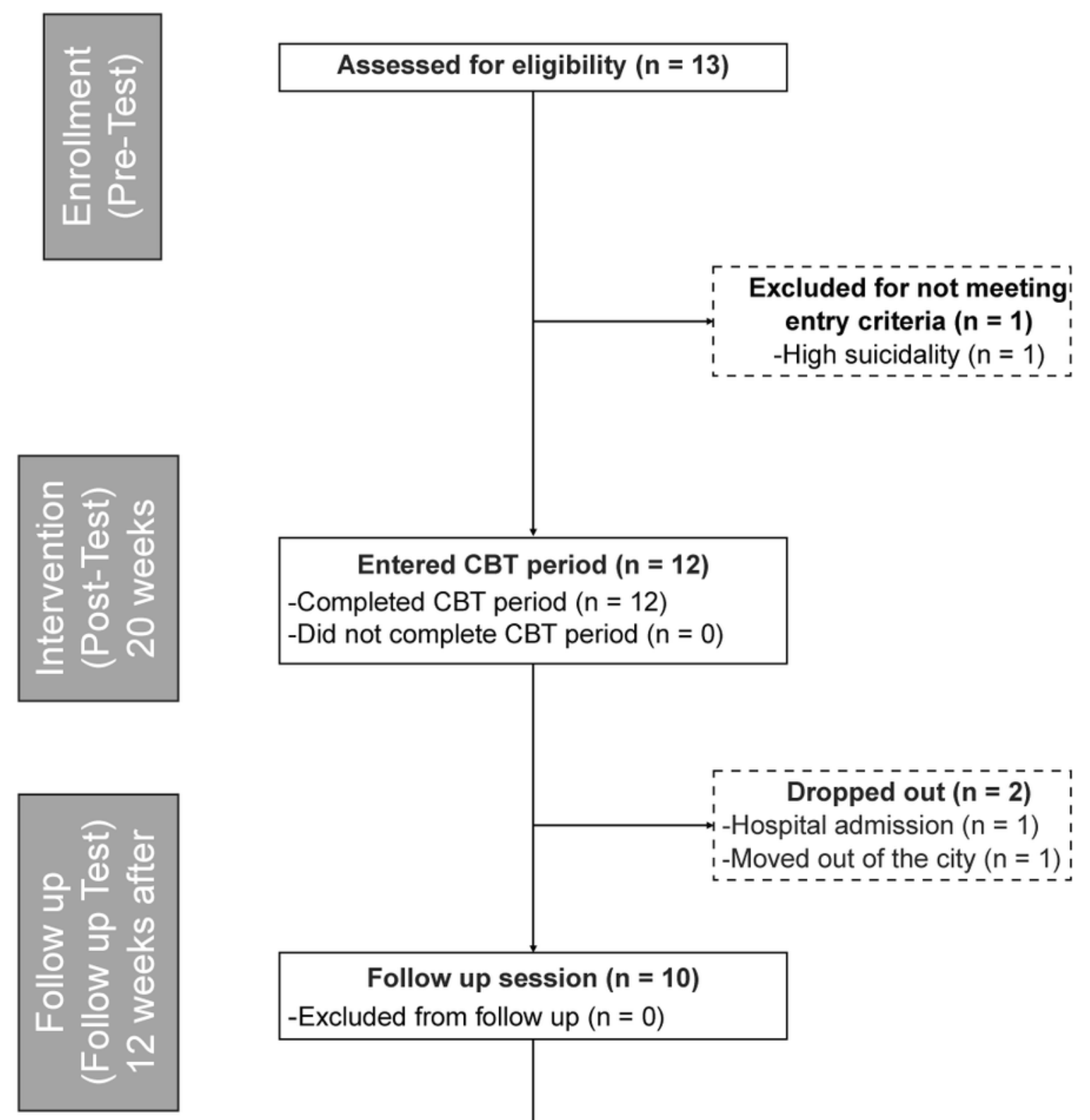

Follow up session $(n=10)$

-Excluded from follow up $(n=0)$
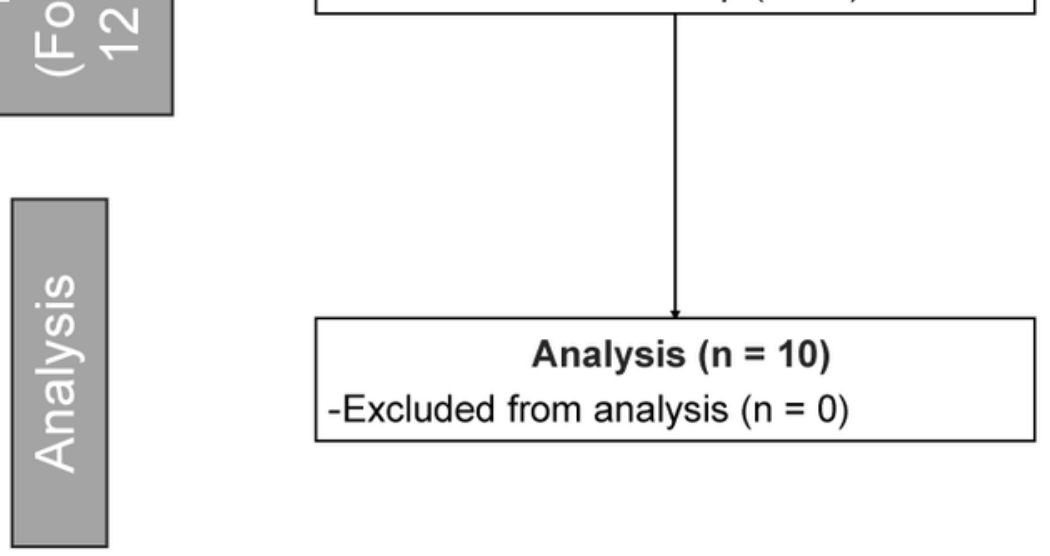

Figure 1

CONSORT flow chart of the clinical trial

\section{Supplementary Files}

This is a list of supplementary files associated with this preprint. Click to download. 
- AdditionalFile1.docx

- AdditionalFile2.docx

- AdditionalFile3.docx

- AdditionalFile4.docx 